\title{
EL ABORTO: UINA MIRADA DESDE LA SALUID PÚBLICA, LOS DERECHOS Y LA JUSTICIA SOCIAL
}

\section{Abortion: A look from the perspectives of pulblic health, rights and social justice}

\section{Joaquín Guillermo Gómez-Dávila, $M D, M S c^{1}$}

Recibido: mayo 4/17 - Aceptado: febrero 12/18

\section{RESUMEN}

El aborto inseguro se considera un problema de salud pública, de derechos y de justicia social. Esto es particularmente certero para las mujeres que viven en países en vías de desarrollo, por lo que se requiere de una salud pública que defienda la dignidad, fomente el ejercicio de los derechos y genere las condiciones necesarias para que las mujeres sean dueñas de su autonomía reproductiva. El artículo tiene como objetivo analizar tres corrientes de justicia distributiva, examina sus fortalezas y contradicciones, y concluye que el desarrollo de capacidades y la justicia social que de este se derivan sería ideal para afrontar de mejor manera el tema del aborto en los países de medianos y bajos ingresos, y, para una salud pública que pretende el mayor grado de salud y bienestar posibles, asegura la satisfacción de todas las condiciones materiales básicas para el florecimiento de las capacidades y, por ende, sería la mejor alternativa para una mayor participación en la construcción de vidas propias; tendría presente la realidad que viven las personas en sus entornos socioculturales, y posibilitaría sacar del espacio privado el mundo femenino, permitir el

1 MSc en Obstetricia y Ginecología, MSc en Epidemiología, Medellín (Colombia). Profesor titular de la Universidad de Antioquia; aspirante a Doctor en salud pública de la misma Universidad.

joaquin.gomez@udea.edu.co debate público sobre dichas cuestiones e impedir que sigan siendo consideradas como cuestiones "naturales" e inmutables de las relaciones humanas, lo que garantizaría una mayor pertinencia en la satisfacción de las necesidades de cada población. También recalca que la justicia social que caracteriza a este enfoque no llegará de arriba, del Estado, sino que requiere de una construcción colectiva, donde los movimientos contrahegemónicos juegan un papel muy importante y hacen parte de la propia construcción de capacidades.

Palabras clave: salud pública, justicia social, derechos humanos, aborto inseguro, utilitarismo, liberalismo, desarrollo de capacidades.

\section{ABSTRACT}

Unsafe abortion is a problem of public health, rights and social justice, particularly so for women living in developing countries. Consequently, public health is called upon to protect dignity, promote the exercise of rights and create the right conditions to ensure that women can have control over their own reproductive autonomy. The article analyses three schools of distributive justice, examines their strengths and contradictions, and concludes that capability building, with its resulting social justice, that derives from these, would be the ideal approach to the issue of abortion in medium and low income countries; and that, for a public health 
system intent of achieving the highest degree of health and wellbeing, it secures the basic material conditions required for capabilities to flourish becoming the best alternative for greater participation in the construction of individual life projects; it would consider the reality of the people in their sociocultural environments and would allow to pull the female world out of the private realm to allow a public debate on these matters and prevent them from being considered as "natural" unchangeable aspects of human relations. This would ensure greater relevance in terms of meeting the needs of each population. The article also highlights that the social justice that characterises this approach will not come from the top, from the State, but requires collective participation, where movements that oppose hegemony play a very important role and are active in building their own capabilities.

Key words: Public health, social justice, human rights, unsafe abortion, utilitarianism, political liberalism, capability building.

\section{INTRODUCCIÓN}

El aborto inseguro es considerado un problema de salud pública (SP), de derechos humanos y de justicia social (JS). A nivel global y regional se ha trabajado intensamente por parte de la comunidad internacional (1-4), incluidos los grupos de mujeres que abogan por sus derechos. Sin embargo, el aborto inseguro persiste como un problema de SP y JS vigente principalmente en el mundo en vías de desarrollo y, particularmente, en América Latina y El Caribe. De los 208 millones de embarazos estimados en el mundo por año, el $41 \%$ (85,3 millones) fueron no deseados, fuente del aborto inseguro. El aborto ha disminuido a nivel global, pasó de 45,5 millones en 1995 a 41,6 en 2003; sin embargo, el número de abortos inseguros apenas se modificó, pasó de 19,9 a 19,7 millones en el mismo periodo. El descenso en el número total de abortos se da principalmente por el descenso en la tasa de aborto seguro, que pasó de 20 a 15 por 1.000 mujeres de 15 a 44 años, mientras la tasa de aborto inseguro apenas pasó de 15 a 14 por 1.000 mujeres en edad fértil, entre los años 1995 y 2003 (5).

Se estima que cerca del 20 al $30 \%$ de las mujeres que se enfrentan a un aborto inseguro presentan infección de los órganos pélvicos, 8 millones sufren complicaciones que requieren tratamiento médico -pero solo 5 millones tienen acceso al mismo-, y 47.000 mueren a consecuencia de complicaciones relacionadas con el aborto (5). El $98 \%$ de estas mujeres viven en países en vías de desarrollo, y se concentran en aquellos con leyes restrictivas que obligan a las mujeres a recurrir a prácticas no seguras y a personal no calificado para realizar el aborto, lo que les impone una mayor carga de enfermedad y muerte. En América Latina la razón de letalidad por aborto es de 30 por cada 100.000 nacidos vivos (5).

En Colombia, a pesar de que la Corte Constitucional, en el año 2006, lo despenalizó (6), aún persiste el aborto inseguro como consecuencia de la poca información, las trabas administrativas, los retrasos en los procesos de atención, y los maltratos y las violaciones de los derechos de las mujeres (7-15). En el país hay 400.000 abortos no seguros por año, y 93.000 complicaciones evitables, que consumen los recursos del sistema de salud (16). Setenta mujeres fallecieron por complicaciones del aborto en 2008 (17) y 27 en 2014, y ocuparon el quinto lugar como causa de muerte materna en este año (18).

La SP como responsable de la salud y el bienestar de las poblaciones debe afrontar el tema del aborto desde una perspectiva de derechos y JS que contribuya al respeto de la dignidad de las mujeres y, por ende, a lograr la mejor salud y bienestar posibles. Por tanto, la SP debe generar las condiciones necesarias para que las mujeres sean dueñas de su autonomía reproductiva. La perspectiva de JS que se asuma es fundamental tanto para las mujeres como para la sociedad, por tanto, se hace necesario analizar dichas perspectivas, en el marco de los derechos, de tal forma que faciliten el avance y contribuyan a la autonomía y el ejercicio pleno de los derechos de las mujeres. El artículo tiene como objetivo analizar 
tres corrientes de justicia distributiva: el utilitarismo, el liberalismo y el desarrollo de capacidades, y compara sus fortalezas y contradicciones; busca demostrar que el desarrollo de capacidades es la más adecuada para afrontar el tema del aborto en los países de la región de Latinoamérica y del Caribe.

\section{CORRIENTES DE LA JUSTICIA DISTRIBUTIVA}

Todos podemos estar de acuerdo acerca de que en la sociedad los bienes se deben distribuir de forma correcta, de tal manera que se evite la injusticia de personas con abundante riqueza y personas en la pobreza absoluta. La justicia distributiva busca la distribución adecuada de los bienes, en otras palabras, aspira a la justicia social (19). A continuación se discute sobre tres formas de justicia distributiva: el utilitarismo, el liberalismo y el desarrollo de capacidades.

El utilitarismo. El enfoque utilitarista de Jeremy Bentham (1748-1832) y John Stuart Mill (18061873) sostiene que la justicia consiste en maximizar la utilidad o el bienestar, en otras palabras, la mayor felicidad para el mayor número de personas (20). Bentham señala que el principio mayor de la moral consiste en maximizar la felicidad, en la medida que, una vez sumado todo, el placer sobrepase al dolor. Debe hacerse aquello que maximice la utilidad, esta última entendida como cualquier cosa que produzca placer o felicidad, y cualquiera que evite el dolor o el sufrimiento. En consecuencia, la moralidad de un acto depende solo de sus consecuencias, se debe hacer aquello que produzca el mejor estado de cosas una vez considerados todos los factores (21).

Para Bentham hay tres principios fundamentales, el primero es que el individuo es la medida de la organización social, dicho de otra forma, la sociedad o comunidad es un "cuerpo ficticio" constituido por la sumatoria de los individuos; en segundo lugar, el individuo está gobernado por el placer y por el dolor, por tanto, un placer puro e intenso, desprovisto de dolor, es la felicidad; y tercero, la búsqueda de la mayor felicidad posible es el fin último, tanto del individuo como de la comunidad; en otras palabras, la vida moral y política se basaban en el placer y el dolor, maximizando el primero y evitando el segundo. Bentham estableció la mayor felicidad de todos como su principio universal, sin embargo, la felicidad de unos puede ocasionar una disminución en la felicidad de otros. Por tanto, nuestro autor consideró como objetivo universal, no la mayor felicidad de todos, sino la del mayor número (22).

Ante este planteamiento existen dos objeciones, la primera consiste en que este enfoque viola los derechos humanos y no respeta la dignidad intrínseca de cada ser humano. Para entenderlo de forma práctica analicemos lo que ocurriría con una mujer que quiere terminar su gestación por cualquiera de las tres causales reconocidas por la Corte Constitucional de Colombia (6). En una sociedad patriarcal, que considera que la razón de ser de los seres humanos es procrearse, y donde un aborto causaría mucho dolor a la mayoría de las personas y solo felicidad -o mejor, menos dolor- a la mujer que recurre a este, la posibilidad de interrumpir la gestación no sería posible. Pero el problema no está en el hecho de aprobar o no el aborto -situación que para los utilitaristas, en un país de mentalidad laica, sería adecuada para evitar pérdida de vidas humanas y efectos negativos sobre la salud-, sino en el hecho de desconocer al individuo al hacer un cálculo utilitarista grupal. En este caso, la Sentencia C-355 de 2006, de la Corte Constitucional, afecta positivamente a los grupos que están en favor del aborto y negativamente a los que están en contra, y crea un enfrentamiento entre grupos, como efectivamente ocurre (23-26). Por tanto, se puede afirmar que el respeto por los derechos y por la dignidad humana va mucho más allá de un simple cálculo utilitario de grupo, donde se invisibiliza al individuo, y, por consiguiente, la propuesta de Bentham no sería razonable (21).

La segunda objeción consiste en que cualquier aspecto con importancia moral se puede transcribir a una escala de valor única, sin que se pierda nada en 
la transcripción. Esta objeción supone que con una unidad común de valor es imposible captar todos los valores necesarios que pueden estar implicados en una decisión (21). Por ejemplo, no es lo mismo tomar la decisión de abortar por una malformación fetal incompatible con la vida, en cuyo caso la mujer y la mayor parte de la sociedad estarían de acuerdo, que hacerlo porque la mujer se siente afectada en su salud mental o porque está en riesgo su propia vida, en donde el balance anterior sería diferente; una escala única de traducción no podría dar cuenta de estos matices y, por ende, sí se perdería mucho en la transcripción.

John Stuart Mill da respuesta a los cuestionamientos realizados a Bentham. Primero, intenta reconciliar los derechos individuales con el utilitarismo al afirmar que las personas deberían ser libres de hacer lo que quieran con tal de que no perjudiquen a otras personas, y el Estado no tiene por qué intervenir en las libertades individuales, ni siquiera para proteger a una persona de sí misma, ni para imponerle la mejor manera de vivir según la mayoría; dicha persona solo tendría que rendir cuentas a la sociedad en aquellos actos que afecten a otros (20).

Según Sandel, "las conjeturas de Mill acerca de los saludables efectos sociales de la libertad son bastante verosímiles, pero no ofrecen una base moral convincente a los derechos individuales" (21), pues el respetar los derechos individuales con el propósito de fomentar el progreso social deja a estos derechos sujetos a la contingencia (21). En otras palabras nuestra sociedad, que mayoritariamente está en contra del aborto, llegaría a la conclusión de prohibirlo, con lo cual se afectarían los derechos individuales de muchas mujeres. Podría afirmarse, además, que favorecer el aborto no fomenta el progreso social y, por tanto, el derecho al aborto quedaría abolido en aras de la mayoría. También, se pasa por alto el hecho de que violar los derechos de un individuo es causarle un mal, independientemente del resultado del bienestar general (21). Por consiguiente, impedir el aborto a una mujer implicaría causarle sufrimiento o incluso la muerte, y violaría los derechos individuales de elegir lo mejor para su vida, negando la dignidad y la libertad de las mujeres para tomar sus propias decisiones, así la mayoría de la sociedad estuviera complacida.

Que el placer sea placer y el dolor sea dolor es uno de los atractivos de la teoría de Bentham, pues la hace muy simple, dado que lo único que tendríamos que medir para saber si algo es mejor o peor es la intensidad y la duración del placer o del dolor (21). Sin embargo, Mill sí cree que se puede hacer una diferenciación más allá de la cantidad e intensidad del placer y el dolor, y evaluar la calidad de estos. Reconoce que hay placeres más valiosos que otros, para lo cual Mill propone que "de dos placeres, si hay uno que es el preferido por todos o casi todos los que han experimentado los dos, sin que medie sentimiento alguno de que se tiene la obligación moral de preferirlo, ese será el más deseable" (21).

Sin embargo, esta argumentación se puede cuestionar basados en nuestras decisiones cotidianas, donde muchas veces elegimos cosas no tan placenteras, pero sí más cómodas o menos exigentes (21). Es evidente que en el caso del aborto muchas veces se toma la decisión menos placentera, e incluso la más dolorosa, situaciones que ponen a prueba la argumentación de Mill y que la desvirtúan.

En conclusión, podemos afirmar que el utilitarismo niega los derechos individuales en pro de un cálculo colectivo, dejando al aborto sujeto a la decisión de la mayoría y no a la decisión de cada mujer, lo que nos dejaría en la situación actual donde muchas sociedades lo prohíben, lo que constituye fuente de aborto inseguro, complicaciones y muerte.

El enfoque liberal. El enfoque liberal tiene dos corrientes, la libertaria y la igualitaria liberal. La corriente libertaria, cuyo representante destacado es Robert Nozick, defiende filosóficamente los principios libertarios y ataca la idea de justicia redistributiva, sostiene que la justicia consiste en respetar la libertad de elegir en un mercado libre (27). Esta corriente defiende la libertad absoluta de los mercados, no por la eficiencia económica, sino 
por la libertad humana. El derecho fundamental de los seres humanos es el derecho a hacer lo que quieran con lo que poseen, y la única restricción es el respeto a que los otros hagan exactamente lo mismo (21).

El enfoque libertario no admite el paternalismo, no se deben hacer políticas para proteger la vida de nadie, pues se viola el derecho de cada individuo a tomar los riesgos que quiera; respecto a legislar sobre la moral señalan que no se puede forzar a los individuos a ser virtuosos; y sobre la redistribución de la renta o el patrimonio manifiestan que el Estado no debe obligar a los individuos a redistribuir sus ganancias, lo que se deja a la voluntad de cada individuo (27).

La corriente igualitaria liberal (John Rawls) sostiene que la justicia consiste en las elecciones hipotéticas que se harían en una situación de partida caracterizada por la igualdad, lo que implica actuar bajo el "velo de la ignorancia", que no es otra cosa que concebir el agente moral de modo que sea independiente de sus fines y apegos particulares (19).

Nozick y Rawls coinciden en la necesidad de la neutralidad del Estado con respecto a los principios de la justicia que define nuestros derechos en el sentido de que no deben basarse en concepciones morales o religiosas particulares (21). Un Estado neutral está íntimamente ligado al elegir libremente, pues para que cada individuo pueda hacerlo requiere de un Estado que sea neutral con respecto a los fines, que no se involucre en las discusiones morales y religiosas, y que deje a cada individuo en libertad de elegir sus valores por sí mismo (21). Sin embargo, una crítica consiste en que el liberalismo deja en el ámbito privado, fuera del alcance de la justicia, todo lo concerniente a la procreación, la crianza, el cuidado de los enfermos y ancianos, y el trabajo doméstico, con lo cual invisibiliza el tema femenino y nos hace preguntar quién determina este límite, sino una mentalidad masculina, burguesa, patriarcal, que luchaba por su derecho de autonomía en las esferas religiosa y económica contra el Estado absolutista, y dejó a la mujer al servicio de su marido y fuera de la esfera pública (28). Hay que reconocer que esta situación ha cambiado, principalmente en los países desarrollados, debido a la lucha de las mujeres que han llevado al espacio público sus temas y han logrado JS, dado que la lucha por que algo sea público es la lucha por la justicia (28).

Otra crítica proviene de los comunitaristas, pues estos defienden las ataduras, una noción más fuerte de comunidad y solidaridad, así como un papel más fuerte del Estado en las cuestiones morales y religiosas (21). En otras palabras, los comunitaristas se comprometen con la vida real de los seres humanos y rechazan ese mundo idealizado que proponen los liberales.

Las críticas a una justicia y unas instituciones sociales ideales van dirigidas a la identificación de una justicia perfecta y a una naturaleza de lo justo, así como a hacer justas las instituciones, ya que omiten las realidades de los individuos concretos; de hecho, puede que no exista acuerdo razonado, incluso en estrictas condiciones de imparcialidad y escrutinio, sobre la sociedad justa que propone Rawls desde su posición original. Por otro lado, para hacer una elección hay que comparar entre situaciones reales y factibles de justicia y no con una situación ideal que probablemente no esté disponible (29). Todo lo anterior lleva a una reflexión de no quedarnos con esquemas ideales, perfectos y atender a la vida de las personas; como dice Sen: "Para la idea de la justicia resulta crucial que tengamos un fuerte sentimiento de injusticia con muchos y diferentes fundamentos, y sin embargo, que no coincidamos en un fundamento particular como razón dominante para el diagnóstico de la injusticia" (29).

Estas dos posiciones, la libertaria y la igualitaria, interactúan permanentemente en la actualidad. Para el sistema de salud colombiano, a pesar de que la Ley 1751 de 2015 consideró la salud como un derecho (30), se está más cerca de los liberales libertarios, y se considera a la salud, en la práctica, como un servicio público y no como un derecho; con un mercado de salud donde los usuarios acceden a los servicios; con un Estado que interviene 
como regulador y no participa en la prestación de servicios, con la aspiración de que la competencia en el mercado produzca ventajas como aumentar la calidad y disminuir los precios (31).

En el caso del aborto podríamos asegurar, según el liberalismo, que sería una elección libre y voluntaria de la mujer, y el Estado sería neutral y evitaría las discusiones morales y religiosas con respecto este y al origen de la vida. Sin embargo, vale la pena preguntarse si en esta situación particular el Estado sí es neutral. Para la religión católica y otras, la vida inicia con la concepción y se debe proteger desde ese momento, por tanto, la neutralidad del Estado no resuelve esta situación y, por el contrario, ha tenido que intervenir clarificando que la vida antes del nacimiento es defendida por la Constitución; sin embargo, su valor no es absoluto per se y se requiere una ponderación de derechos cuando entran en conflicto el derecho a la vida del no nacido y el derecho de una persona natural (6). Sin embargo, esta neutralidad frente a los argumentos religiosos se podría interpretar como desestimar el argumento moral de la Iglesia y, por consiguiente, toma posición dejando de ser neutral con respecto al aborto. Adicionalmente, la argumentación de la libre elección se resquebraja por el hecho de que una mujer pobre, sin educación, sin trabajo y en lucha por la supervivencia -consecuencias del neoliberalismo económico-, no puede tomar decisiones totalmente libres.

Según Sandel, esto no equivale a defender la prohibición del aborto, sino a reconocer que la neutralidad y la libertad de elección no son razones suficientes para aceptar el derecho a abortar (21). Un argumento a favor es que los movimientos de mujeres han llevado el tema del aborto del ámbito privado al público, centrándose en las relaciones asimétricas de poder entre hombres y mujeres que regula esa división entre lo público y lo privado (28), a fin de lograr el reconocimiento de la autonomía de la mujer y su dignidad, esta última entendida no desde una visión ontológica y teleológica, sino desde una perspectiva evolutiva, abierta incluso a la transformación progresiva, deliberada y libremente consentida de la "naturaleza humana" comprendida como una realidad empírica, producto de la evolución y de la historia (32). Por consiguiente, prohibir o aceptar el aborto está lejos de poderse abordar desde una posición neutral y, por el contrario, obedece a una "lucha evolutiva" filosófica, ética, moral y religiosa por hacer pública la opresión privada, situación que se puede vivir a flor de piel en el caso colombiano.

Desde mi perspectiva, la mejor opción para un sistema de salud sería la JS del liberalismo igualitario, que implica que el Estado asuma la responsabilidad de la salud, la educación, el trabajo y el ingreso básico, entre otras, para permitir que los individuos decidan en libertad. Sin embargo, se debe señalar que son los individuos los que hacen posibles las instituciones, incluido el propio Estado, individuos que han cuestionado los Estados de bienestar. Por consiguiente, esta visión de JS nos dejaría en la situación actual donde grupos de derecha están accediendo al poder por decisión "libre" de los individuos, profundizando el neoliberalismo, una disminución del Estado y una pauperización de la mayoría de la población del planeta, todo en función de incrementar el capital como fin último, y en detrimento de la solidaridad y de la satisfacción de las necesidades básicas de los seres humanos, convirtiéndolos en un medio para los dueños del capital y no en un fin en sí mismos.

Las capacidades y el desarrollo humano. Amartya Sen, un economista liberal, plantea la teoría de las capacidades como desarrollo humano y las define como el conjunto de posibilidades que están a disposición de una persona respecto a lo que ella puede hacer o ser (33). La capacitación de la persona para un modo de ser autónomo conforma el objetivo práctico y político del enfoque de las capacidades. Las libertades individuales obtienen de esta manera una función crítico-social. En palabras de Sen, dichas libertades son la piedra angular del enfoque mismo y, en un sentido más amplio, "el éxito de una sociedad ha de evaluarse, desde este punto de vista, principalmente en función de 
las libertades fundamentales de que disfrutan sus miembros" (34).

Sen afirma que el desarrollo puede concebirse como la expresión de las libertades individuales reales de las que disfrutan los individuos en una sociedad, y hace una diferenciación con la concepción reduccionista de desarrollo centrado en el crecimiento económico (34). El enfoque del desarrollo de Sen se centra en la vida buena como fin, es decir, en una concepción perfeccionista o, si se quiere, evolucionista de la naturaleza humana. Considera la existencia de un núcleo que define la naturaleza humana, y las facultades y capacidades agrupadas en dicho núcleo son susceptibles de desarrollo y perfeccionamiento (33). En este sentido es fundamental eliminar fuentes de privación de las libertades como la pobreza, la falta de educación, la escasez de oportunidades económicas y las privaciones sociales sistemáticas como servicios públicos, la intolerancia y los Estados autoritarios (34). Todas estas fuentes de privación restringen la libertad e impiden vivir una vida buena. El ejemplo perfecto es el de la mujer que está pensando en abortar y que vive en una sociedad machista y patriarcal, subyugada a la voluntad del hombre, con escasa o ninguna educación, dedicada a las labores del hogar, dependiente del ingreso masculino, sin acceso real a los servicios de salud y específicamente a los servicios de salud reproductiva, como anticoncepción y aborto seguro; esta es una mujer que no desarrollará sus capacidades como ser humano y vivirá su vida al servicio del hombre y de sus hijos y, por tanto, no vivirá una vida buena, o por lo menos una vida que ella hubiera decidido vivir, y ante la decisión de abortar buscará los medios a su alcance para hacerlo, recurrirá a un aborto inseguro y se someterá al riesgo de complicaciones y muerte.

La libertad es fundamental para el proceso de desarrollo humano y este desarrollo se puede evaluar al verificar el grado de libertad alcanzado por los individuos en una sociedad, así como por la libre agencia de estos, los cuales son importantes debido a que las libertades son interdependientes, se refuerzan mutuamente, y son estas las que hacen que la agencia de los individuos sea un verdadero motor de desarrollo, pues las personas o los agentes con suficientes oportunidades sociales pueden configurar en realidad sus propios destinos y ayudarse solidariamente (34). En otras palabras, el desarrollo individual y social asegura las distintas libertades como las políticas, económicas y culturales, entre otras (33). Pero más allá de dichas conexiones, lo que los individuos pueden conseguir depende de las oportunidades económicas, las libertades políticas, las fuerzas sociales y las posibilidades que brindan la salud, la educación, el fomento y el cultivo de las iniciativas (34). Lo anterior implica que todos los individuos merecemos tener acceso a salud y educación, a oportunidades económicas, libertades políticas y, a su vez, estas libertades se logran a partir de la libertad para participar en las decisiones sociales y en la elaboración de las decisiones públicas que impulsan el progreso de estas oportunidades. Asimismo, el tener salud y educación contribuye al desarrollo económico y este, a su vez, contribuye con estas libertades. Es así como nuestra mujer sometida a una vida prestada podría tener acceso a educación, salud sexual y reproductiva, ingresos económicos, a la posibilidad de la libre asociación y la participación política, y autonomía para la toma de decisiones conscientes, lo que le permitiría vivir la vida que ella decida vivir y no la que la sociedad machista y patriarcal le ha asignado, permitiéndole planear el tener o no hijos y su número, y, por tanto, muy posiblemente no hubiera llegado a requerir un aborto, pues estaría planificando y, si lo hubiera requerido por un fallo en su método anticonceptivo (2), lo habría solicitado tempranamente y de manera segura.

Sen reconoce el papel que juega el mercado en el desarrollo, pero lo pone en su debido lugar aseverando que "la contribución del mecanismo del mercado al crecimiento económico es importante, por supuesto, pero solo una vez que se reconoce la importancia directa de la libertad para intercambiar palabras, bienes o regalos" (34), o como diría Adam 
Smith, citado por Sen, "la libertad para realizar intercambios y transacciones constituye en sí misma una parte de las libertades básicas que los individuos tienen razones para valorar" (34). Lo anteriormente expuesto no quiere decir que no se reconozca la importancia del mercado y su papel fundamental en el crecimiento económico, sino que también se reconoce el papel de la ayuda social, la legislación o la intervención del Estado para enriquecer la vida humana y, para hacerlo, se requieren valores, que están influidos a su vez por los debates públicos y las interrelaciones sociales, y estas necesitan libertades de participación. Por tanto, la propuesta de Sen contiene una exigencia a la teoría de la JS, pues su concepto de persona se refiere de manera explícita a las condiciones institucionales y económicas que son necesarias para el desarrollo de la naturaleza humana (34). Lo expuesto implicaría que el Estado no adoptara una posición neutral frente al mercado y, por el contrario, interviniera en la protección de los espacios necesarios para el desarrollo de las capacidades básicas de la población, y que la mujer de nuestro ejemplo tuviera las posibilidades necesarias para el desarrollo de sus capacidades y se convirtiera en un ser autónomo, que toma sus propias decisiones y que lucha por vivir una vida digna de ser vivida, como ocurre en los países desarrollados y, por reflejo, en algunos estratos de la población en aquellos en vías de desarrollo.

La teoría de Sen se basa en las capacidades humanas aristotélicas que conciben a los recursos económicos en función de la realización de oportunidades, tal como la presenta Aristóteles en la Ética nicomáquea: "la vida de negocios [destinada a hacer dinero], es algo violento [es en sí algo forzado, artificial] y es evidente que la riqueza no es el bien que buscamos, pues es útil en orden a otro [es un medio para un fin]" (35). El significado funcional de los recursos económicos consiste en que deben posibilitar la consecución del máximo bien, que es la felicidad y la justicia, definida la felicidad como aquel estado de perfeccionamiento de lo humano, donde se realiza la función propia del hombre; para
Aristóteles, la realización de este ideal de vida es "una actividad del alma de acuerdo con la virtud" (35). Lo que ratifica que el dinero es un medio y no un fin, y que el desarrollo de capacidades requiere de unos medios que propicien y favorezcan su crecimiento para que las personas puedan llegar a ser verdaderos seres humanos, fines en sí mismos y no medios para lograr los fines de otros hombres. En nuestro caso ello implicaría que nuestra mujer tomara sus propias decisiones y no quedara a merced del hombre, como medio para lograr lo que este quiere, y que ambos a su vez fueran autónomos y no medios de un sistema productivo que los explota y los condena a ser medios para acrecentar el bienestar de otros, los capitalistas.

La capacidad, tomada en el sentido general de poder ser de un modo activo, necesita estar rodeada por condiciones que la posibiliten. Por ello no basta con disponer de muchas y variadas opciones para elegir, sino que se trata ante todo de estar en condiciones de hacerse con las posibilidades y realizarlas de manera autónoma. Nuestra mujer debería ser capaz de elegir si quiere o no tener hijos y su número, debería poder decidir trabajar, estudiar y ser lo que ella realmente quiera ser. La política de la JS se ve entonces confrontada con la tarea de ofrecerle al individuo las condiciones materiales e institucionales necesarias para que pueda realizar las opciones que libremente ha escogido, y romper el círculo de la imposición y de la degradación de los seres humanos.

$\mathrm{Al}$ analizar lo dicho hasta el momento sobre el enfoque de capacidades es claro que se requiere una teoría de la JS que trascienda los modos esquemáticos de esa JS inalcanzable y casi con seguridad no unánime, alejada de la vida cotidiana de los seres humanos (19); una teoría que tenga en cuenta la vida de las sociedades, la vida de los individuos, sus capacidades y funciones, y que corrija las profundas injusticias presentes en el mundo liberal actual. Sen afirma: "los requisitos de una teoría de la justicia incluyen poner la razón en juego en el diagnóstico de la justicia y la injusticia" (29), que no es otra 
cosa que concentrarse en la vida cotidiana de las personas y observar las injusticias como motor de la justicia y no presumir un comportamiento ideal que en última instancia es inalcanzable e irreal. Así, nuestro Estado estaría concentrado en corregir las causas de injusticia como la falta de educación, de salud, de empleo, y propiciaría el acercamiento de estas funciones básicas a las comunidades excluidas, a fin de favorecer el cultivo de las capacidades verdaderamente humanas y romper los círculos de no funciones, no capacidades, no vida digna, no vida buena.

Esta teoría de la justicia, propuesta por Sen, también se remonta a la concepción aristotélica de la fragilidad humana, de concebir al ser humano con un potencial de capacidades que requiere cuidados materiales para que las pueda desarrollar. Igualmente, la teoría de las capacidades se basa en la concepción estoica de la dignidad humana, todos los seres humanos somos iguales y merecemos un trato digno. Es la fusión de estas dos corrientes, la fragilidad humana de Aristóteles y la dignidad humana de los estoicos, en la que se basa el enfoque de las funciones y capacidades (36). Estos mismos argumentos fueron retomados por Adam Smith, quien asume las posturas estoicas, pero rechaza la doctrina de la invulnerabilidad, también estoica, y a donde recurrió a Aristóteles para dar cuenta de todas las condiciones materiales necesarias -la familia, los amigos, la educación, entre otras- para el florecimiento humano. De hecho Smith, se preguntó por el papel del Estado para favorecer el desarrollo de las facultades humanas respetando la igualdad entre las personas, advirtió sobre la cooptación del Estado por las élites dueñas del dinero y propuso leyes para evitarlo; impulsó la educación pública y gratuita en una época en que solo existía en Escocia, pero no en el Reino Unido (36). En su libro Investigación de la naturaleza y causa de la riqueza de las naciones dijo: "pero la misma pobreza, aunque no sea obstáculo para la generación, lo es muy grande para la crianza de los hijos. Prodúcese y germina la tierna planta, pero si es en un suelo muy frío o en un clima muy destemplado, a poco tiempo se marchita y muere" (37). Como dice Martha Nussbaum, Smith intuyó que las facultades humanas llegan al mundo en un estado incipiente y requieren de ayudas para desarrollarse, tanto físicas (nutrición, salud), como mentales (educación, tiempo libre), para que maduren y estén a la altura de la dignidad humana (36).

Nussbaum profundiza en el tema de las capacidades y enumera una lista de ellas. Afirma la autora que las capacidades son transculturales y a las cuales se puede adherir independientemente de la concepción política, sin aceptar ninguna, una visión metafísica del mundo en particular, sin ninguna ética o visión religiosa, o de la persona o de la naturaleza humana (38). Afirma que se requieren todas las capacidades y no una en particular, pues todas son importantes y, además, las capacidades están relacionadas de varias y complejas maneras, lo que hace imposible promocionar una por encima de las otras (38).

Las capacidades son: la vida, ser capaces de vivir hasta el final una vida humana de duración normal; la salud corporal, que incluye la salud sexual y reproductiva, la nutrición y un techo adecuado; la integridad corporal, ser capaces de movernos libremente a cualquier lado, y que los límites del propio cuerpo sean tratados como soberanos, con seguridad ante el asalto, incluido el abuso sexual y la violencia doméstica; los sentidos, imaginación y pensamiento, ser capaces de sentir, imaginar y pensar de forma verdaderamente humana, para lo que se requiere educación; las emociones, ser capaces de tener vinculaciones con cosas y personas fuera de nosotros mismos, amar a quien nos ama y cuidar de nosotros; la razón práctica, ser capaces de una concepción del bien y comprometernos en una reflexión crítica sobre la propia vida; la afiliación, ser capaces de vivir con y hacia otros, poseer las bases del respeto a nosotros mismos y de la no humillación; las otras especies, ser capaces de cuidar los animales, las plantas y el mundo natural; el juego, ser capaces de reír y jugar; y el control del propio 
entorno, tanto político como material (38). Si el Estado asumiera el compromiso de crear la base social para el desarrollo de capacidades, se generaría una situación casi ideal, donde la mujer asumiría su vida, su salud, su integridad, sus emociones, su razón práctica, su afiliación, su derecho al juego, el control de su entorno y su relación con la naturaleza, de manera consciente y reflexiva, tomando decisiones autónomas y mejorando la situación, no solo personal, sino colectiva, lo que afectaría a todos los habitantes del planeta.

\section{CONCLUSIÓN}

El desarrollo de capacidades, y la JS que de este se deriva, sería ideal para afrontar el tema del aborto en nuestro país, pues una SP que pretende el mayor grado de bienestar posible aseguraría la satisfacción de todas las condiciones materiales básicas para el florecimiento de las capacidades y, por ende, una mayor participación en la construcción de nuestras propias vidas; tendría presente la realidad que viven las personas en sus entornos socioculturales, lo que garantizaría una mayor pertinencia en la satisfacción de las necesidades de cada población. Sin embargo, no sobra recalcar que la JS que caracteriza a este enfoque no llegará de arriba, del Estado, sino que será una construcción colectiva, donde los movimientos contrahegemónicos (39) juegan un papel muy importante y hacen parte intrínseca de la propia construcción de las capacidades.

Como ejemplo de ello, los movimientos feministas y de mujeres deben continuar sacando del espacio privado lo concerniente a lo femenino, a donde fueron confinados por el Estado liberal, y fomentar el debate público e impedir que sigan siendo vistas como cuestiones "naturales" e "inmutables de las relaciones humanas" (28). Por consiguiente, "cuestionar la distinción del discurso moral y político contemporáneo en la medida en que privatiza estas cuestiones es capital para la lucha de las mujeres que buscan hacer públicas estas cuestiones" (28), y articularlas con movimientos globales $(39,40)$ es propiciar un espacio de debate global a favor de la dignidad humana para todas las mujeres.

\section{REFERENCTAS}

1. Organización Mundial de la Salud (OMS). 57 Asamblea Mundial de la Salud: Ginebra, 17-22 de mayo de 2004. Ginebra: OMS; 2004.

2. Organización Mundial de la Salud (OMS). Aborto sin riesgos: guía técnica y de políticas para sistemas de salud. Ginebra: OMS; 2012.

3. World Health Organization (WHO). Unsafe abortion: global and regional estimates of the incidence of unsafe abortion and associated mortality in 2008. 6th ed. Who. Geneva: WHO; 2008 [visitado 2018 ene 12]. Disponible en: http://whqlibdoc.who.int/ publications/2011/9789241501118_eng.pdf

4. Naciones Unidas. Informe de la Conferencia Internacional sobre la Población y el Desarrollo El Cairo, 5 a 13 de septiembre de 1994. El Cairo: Naciones Unidas; 1994.

5. Guttmacher Institute. Aborto a nivel mundial: una década de progreso desigual. Nueva York: Guttmacher Institute; 2009 [visitado 2018 ene 12]. Disponible en: http://www.clacaidigital.info:8080/xmlui/bitstream/ handle/123456789/169/Entire Monograph 2010 ES.pdf? sequence $=1$

6. Corte Constitucional de Colombia. Sentencia C-355/06, M. P. Jaime Araújo Rentería y Clara Inés Vargas Hernández; 2006 [visitado 2018 ene 12]. Disponible en: http://www.corteconstitucional.gov. co/relatoria/2006/C-355-06.htm

7. Corte Constitucional de Colombia. Auto 279/09, M. P. Jorge Iván Palacio Palacio; 2009 [visitado 2018 ene 12]. Disponible en: http://www.corteconstitucional. gov.co/RELATORIA/Autos/2009/A279-09.htm

8. Corte Constitucional de Colombia. Sentencia T-209/08, M. P. Clara Inés Vargas Hernández; 2008 [visitado 2018 ene 12]. Disponible en: http:/www.corteconstitucional. gov.co/relatoria/2008/t-209-08.htm

9. Corte Constitucional de Colombia. Sentencia T-301/16, M. P. Alejandro Linares Cantillo; 2016 [visitado 2018 ene 12]. Disponible en: http://www.corteconstitucional. gov.co/relatoria/2016/t-301-16.htm

10. Corte Constitucional de Colombia. Sentencia T-585/10, M. P. Humberto Antonio Sierra Porto; 2010 [visitado 2018 ene 12]. Disponible en: http://www.corteconstitucional.gov.co/relatoria/2010/T-585-10.htm 
11. Corte Constitucional de Colombia. Sentencia T-627/12, M. P. Humberto Antonio Sierra Porto; 2012 [visitado 2018 ene 12]. Disponible en: http://www.corteconstitucional.gov.co/relatoria/2012/t-627-12.htm

12. Corte Constitucional de Colombia. Sentencia T-841/11, M. P. Humberto Antonio Sierra Porto; 2011 [visitado 2018 ene 12]. Disponible en: http://www.corteconstitucional.gov.co/RELATORIA/2011/T-841-11.htm

13. Corte Constitucional de Colombia. Sentencia T-988/07, M. P. Humberto Antonio Sierra Porto; 2007 [visitado 2018 ene 12]. Disponible en: http://www.corteconstitucional.gov.co/relatoria/2007/T-988-07.htm

14. Defensoría del Pueblo. La tutela y los derechos a la salud y la seguridad social. Bogotá: Defensoría del Pueblo; 2014.

15. Vásquez Zamorano CH, García Burbano IC. Barreras en el acceso a la interrupción voluntaria del embarazo. Cali: Universidad ICESI; 2013 [visitado 2018 ene 12]. Disponible en: http://repository.icesi.edu.co/ biblioteca_digital/handle/10906/76501

16. Palacios Vicario B, Sánchez Gómez MC, Gutiérrez García A. Evaluar la calidad en la investigación cualitativa. Guías o checklists. Actas del $2^{\circ}$ Congreso Nacional sobre Metodología de la Investigación en Comunicación. 2013;3:581-96.

17. Ministerio de Salud y Protección Social. Prevención del aborto inseguro en Colombia. Protocolo para el sector salud. Bogotá: UNFPA; 2014 [visitado 2018 ene 12]. Disponible en: https://www.minsalud.gov. $\mathrm{co} /$ sites/rid/Lists/BibliotecaDigital/RIDE/VS/PP/SMProtocolo-IVE-ajustado-.pdf

18. DANE. Defunciones maternas, por grupos de edad, según departamento de residencia y grupos de causas de defunción (lista de causas agrupadas 6/67 CIE - 10 DE OPS); 2014 [visitado 2018 ene 12]: 3. Disponible en: http://www.dane.gov.co/index.php/estadisticaspor-tema/salud/nacimientos-y-defunciones/defunciones-no-fetales/defunciones-no-fetales-2014

19. Rawls J. Los principios de la justicia. En: Teoría de la justicia. México D.F.: Fondo de Cultura Económica; 1995. p. 62-117.

20. Mill JS. Qué es el utilitarismo. En: El utilitarismo. Barcelona: Altaya; 1995. p. 44-75.
21. Sandel M. Justicia ihacemos lo que podemos? 2 ed. Barcelona: Penguin Ramdon House; 2011.

22. Rivera-Sotelo A-S. El utilitarismo de Jeremy Bentham: ¿fundamento de la Teoría de León Walras? Cuad Econ. 2011;XXX(55):55-76.

23. Caracol Radio. La Corte le pide respeto a la Iglesia por el fallo sobre el aborto; 2006 [visitado 2018 ene 12]: 1. Disponible en: http://caracol.com.co/radio/2006/05/12/ nacional/1147410000_285602.html

24. Caracol Radio. Centenares de personas respaldaron la marcha en contra del aborto; 2016 [visitado 2018 ene 12]: 1. Disponible en: http://caracol.com.co/emisora/2016/05/08/bucaramanga/1462659121_064314. html

25. El Mundo. Excomulgarán a los magistrados; 2006 [visitado 2018 ene 12]: 1. Disponible en: http://www. elmundo.com/portal/resultados/detalles/?idx $=19197$

26. Caracol Radio. Hoy Colombia marcha contra el aborto; 2014 [visitado 2018 ene 12]: 1. Disponible en: http://caracol.com.co/radio/2014/05/17/regional/1400309520_228671.html

27. Nozick R. Anarquía, estado y utopía. New York: Basic Books; 1974.

28. Benhabib S. El ser y el otro en la ética contemporánea. Zadunaisky G, editor. Barcelona: Gedisa; 2006.

29. Sen A. La idea de la justicia. México D.F.: Taurus; 2009.

30. Congreso de Colombia. Ley Estatutaria 1751 de 2015: Por medio de la cual se regula el derecho fundamental a la salud y se dictan otras disposiciones. Diario Oficial. 2015;CL(49427):1-5.

31. Congreso de la República de Colombia. Ley 100 de 1993: Por la cual se crea el sistema de seguridad social integral y se dictan otras disposiciones. Diario Oficial. 1993;CXXIX(41148):1-93.

32. Hottois G. Dignidad humana y bioética. Un enfoque filosófico crítico. Rev Colomb bioética. 2009 [visitado 2018 ene 12]; 4(2):53-83. Disponible en: http://www. redalyc.org/articulo.oa? $\mathrm{id}=189214316003$

33. Saldarriaga Madrigal AE. El sujeto activo: antropología política en Amartya Sen. Eidos. 2010;(13):54-75.

34. Sen A. Desarrollo y libertad. Buenos Aires: Planeta; 2000.

35. Aristóteles. Ética nicomaquea. Buenos Aires: Lozada; 2007. 
36. Nussbaum MC. Crear capacidades. Barcelona: Book Print; 2012.

37. Smith A. Investigación de la naturaleza y causas de la riqueza de las naciones, tomo III. Alonso Ortiz J, editor. Investigación de la naturaleza y causas de la riqueza de las naciones. Valladolid; 1794 [visitado 2018 ene 12]. Disponible en: http://cataleg.ub.edu/record $=b$ 1846341 S1*cat \%5Cnhttps://www.marxists.org/ espanol/smith_adam/1776/riqueza/smith-tomo1.pdf
38. Nussbaum MC. Las mujeres y el desarrollo humano. Bernet R, editor. Barcelona: Herder; 2002.

39. Vargas V. El movimiento feminista y el movimiento de mujeres en el contexto de globalización. Chacarera. 2008 [visitado 2018 ene 12];36:44-8. Disponible en: http://bibliotecavirtual.clacso.org.ar/Peru/cmp-floratristan/20120824030721/movfem3 \%0A6.pdf

40. De Sousa Santos B, Rodríguez Garavito CA. El derecho y la globalización desde abajo. Barcelona: Anthropos; 2007. 